XIII" siècles", Académie des Inscriptions $\Xi$ Belles Lettres. Comptes rendus des séances, 2000, fasc. 1, Janvier-Mars, 437-457.

Baldwin, John W., ,Étienne de Gallardon and the cartulary of Bourges“, in: Kosto, Adam J. / Winroth, Anders (Hgg.), Charters, Cartularies and Archives. The Preservation and Transmission of Documents in the Medieval West, Proceedings of a Colloquium of the Commission Internationale de Diplomatique, Princeton and New York, 16-18 September 1999, Toronto 2002, 127 (kurze Zusammenfassung des Aufsatzes in Viator).

\title{
Überlieferung:
}

Paris, BnF, nouv. acq. lat. 1274, 13. Jh., fol. 298-299 (Chartular der Kathedrale von Bourges).

\section{R11. Anonymus}

Dialogus clerici et laici contra persecutores ecclesiarum

Rep: RepFont 4, 188-189; De Visch 58-60.

Studie: Kapitel 3.4.2., 3.4.4.

Incipit: Licet characterem, quo ego insignitus sum, tu non geras nec acceperis...

Explicit:... ille vos illuminet et auferat velamen de cordibus vestris, ut nobiscum valeatis videre rectum. Quod ipse praestare dignetur, qui cum patre et spiritu vivit et regnat Deus.

Autor: Der Codex unicus nennt keinen Autornamen. Wegen der kanonistischen Kenntnisse, die der Text verrät, vermutete Maier, der Verfasser sei ein Weltkleriker am Kölner Hochstift gewesen (Ed. Maier, 15-16). Der Überlieferungsbefund bekräftigt diese Vermutung. Der Dialogus befindet sich in einer Sammlung von päpstlichen Mandaten der Jahre 1202 bis 1208 aus der Kanzlei Innozenz' III. (zwei Aktenstücke aus dem Jahr 1213 wurden wohl später hinzugefügt). Die Mehrzahl dieser Mandate steht im Zusammenhang mit dem Streit um die Nachfolge Heinrichs VI. und dessen Auswirkungen in Köln (dazu vgl. „Inhalt" ${ }^{6}$ ). Ein Kleriker der Kanzlei (der Autor?) hat wohl den Dialogus mit Aktenstücken verwandten Inhalts zusammengestellt (ähnlich ist Étienne de Gallardon verfahren, siehe R10).

Wenig überzeugend ist Stehkämpers Zuschreibung an Caesarius von Heisterbach (Stehkämper, 95-96). Thema und Stil sind von Caesarius ${ }^{6}$ Sprache und Interessen weit entfernt. Einziger Hinweis in dieser Richtung ist die Erwähnung eines Dialogs contra haereticos huius temporis et 
errores eorum im Werkkatalog des Caesarius (op. xxv, Hilka 7). Allerdings passt diese Inhaltsangabe nicht zu dem Dialogus clerici et laici.

Datierung: Im Text wird die Ausführung eines päpstlichen Mandates vom 15. März 1206 am 2. April 1206 erwähnt, jedoch nicht weitere für den Inhalt relevante Ereignisse der zweiten Hälfte des Jahres, weshalb Maier eine Entstehung zwischen dem 2. April und Ende Juli 1206 postuliert (Ed. Maier, 14).

Inhalt: Der Dialog nimmt Bezug auf die Umstände nach dem Tod Kaiser Heinrichs VI. und der Doppelwahl des Jahres 1198. Der Kölner Erzbischof, Adolf I. von Elten, hatte zuerst Partei für Otto von Braunschweig ergriffen, dennoch 1205, verärgert über die Versuche Papst Innozenz' III. in die Wahl einzugreifen, offen seine Unterstützung für Philipp von Schwaben erklärt. Der Papst, der damals den Welfen Otto unterstützte, exkommunizierte den Kölner Bischof, ließ ihn absetzen und einen neuen Erzbischof wählen. Ein Kleriker und ein Laie diskutieren im Dialog diese Geschehnisse in Köln, wobei der Kleriker die führende Rolle im Gespräch hat: Er macht die längsten Ausführungen, während der Laie ihm kaum Argumente entgegensetzt. Zuerst erörtert der Kleriker die Rechtmäßigkeit kirchlicher Strafen bei weltlichen Vergehen. Von der allgemeinen Erörterung kommt der Kleriker zur Exkommunizierung Adolfs, die er verteidigt, bis der Laie ihm zustimmt. Weitere Aspekte, die der Laie kritisiert, sind: die Absetzung Adolfs, die Wahl eines neuen Erzbischofs und die päpstliche Verhängung von Exkommunikation und Interdikt gegen die Grafen, die Adolf weiterhin unterstützten. Der Kleriker diskutiert einen Punkt nach dem anderen, wobei er die päpstlichen Entscheidungen verteidigt. Der Laie zeigt sich am Ende überzeugt. Der Dialog endet mit einer predigtartigen Tirade des Klerikers, in der er einen weniger situationsbezogenen Ton anschlägt und seiner Hoffnung Ausdruck gibt, dass die Parteigänger Adolfs wieder zur Einsicht kommen.

\section{Editionen:}

Boehmer, Joh. Friedrich, Fontes rerum germanicarum. Geschichtsquellen Deutschlands. III. Martyrium Arnoldi archiepiscopi Moguntini und andere Geschichtsquellen Deutschlands im zwölften Fahrhundert Bd. 3, Stuttgart 1853, 400-407. Text ohne kritischen Apparat.

Waitz, Georg (Hg.), Chronica Regia Coloniensis (Annales Maximi Colonienses) cum continuationibus in monasterio S. Pantaleonis scriptis et aliisque historiae Coloniensis monumentis, MGH script. in us. schol. [18], Hannover 1880 (ND Hannover 1978), 316-322. Lesetext mit spärlichem Apparat. 